\title{
DESENVOLVIMENTO SUSTENTÁVEL E TURISMO NO ESPAÇO RURAL: UMA PERSPECTIVA EXPLORATÓRIA NO TRIANGULO CRAJUBAR
}

\author{
Camila Pereira Brigido Rodrigues ${ }^{1}$ \\ Denis Fernandes Alves ${ }^{2}$ \\ Maria Daniele Cruz dos Santos ${ }^{3}$ \\ José Márcio Santos ${ }^{4}$
}

\section{RESUMO}

Tem-se o turismo como uma nova forma de ocupação não agrícola dentro do meio rural, sendo tema de grandes debates e fazendo com que ocorra ações de políticas públicas para o desenvolvimento do campo. Por ser uma ramificação do setor da economia global que mais cresce, o Turismo Rural no Estado do Ceará, traz consigo o desenvolvimento local, além de gerar emprego e renda. O objetivo desse trabalho é discutir algumas proposições para os municípios que compõe o triângulo Crato, Juazeiro do Norte e Barbalha (CRAJUBAR), no interior do Estado do Ceará, e como a exploração do Turismo Rural sustentável é de grande valia para o desenvolvimento de famílias camponesas. Optou-se por uma metodologia de análise explanatória, expondo apenas algumas questões, pois a exploração de tal forma de turismo vem apenas começando a ganhar força na região. Tendo a noção que o Turismo Rural é uma importante tática de desenvolvimento dos pequenos e médios agricultores abre-se espaço para discutir políticas públicas que se adequem a região, fazendo com que essa forma de turismo ganhe cada vez mais lugar, tendo assim, por consequência além do desenvolvimento do espaço rural o desenvolvimento da região como um todo.

Palavras-Chave: Desenvolvimento sustentável. Turismo Rural. CRAJUBAR.

Recebido em: 31/03/2016 | Aceito em: 02/08/2016

\footnotetext{
${ }^{1}$ Graduada em Economia pela Universidade Regional do Cariri - URCA, Mestranda em Economia Rural pela Universidade Federal do Ceará - UFC e bolsista Capes. E-mail: pbr.camila@gmail.com

${ }^{2}$ Graduando em Economia pela Universidade Regional do Cariri - URCA e Bolsista de Iniciação Cientifica do Programa Integral de Bolsas de Iniciação Cientifica da Universidade Regional do Cariri PIBIC/URCA. E-mail: denis_fernandes@outlook.com
}

${ }^{3}$ Graduada em Economia pela Universidade Regional do Cariri - URCA, Pós-Graduanda em Gestão Financeira e Consultoria Empresarial pela URCA e Professora do departamento de Economia da Universidade Regional do Cariri. E-mail: danielecruzeconomia@gmail.com

\footnotetext{
${ }^{4}$ Professor Assistente da Universidade Regional do Cariri (URCA), Mestre em Economia pela Universidade Federal da Paraíba (UFPB) e Graduado em Economia pela Universidade Regional do Cariri (URCA). E-mail: jmarcio.santos@hotmail.com
}

Ciência e Sustentabilidade - CeS | Juazeiro do Norte v. 2, n. 1, p. 82-102, jan/jun 2016 I ISSN 2447-4606 


\section{INTRODUÇÃO}

Desde os anos 1990, vem surgindo uma ampla discussão em torno da organização da produção agrícola no espaço rural. A modernização do campo provoca mudanças significativas - novas técnicas de colheita, mecanização, inovações no plantio - fazendo surgir um novo contexto no espaço campesino, amarrado ao meio urbano. Esse espaço deixa de ser puramente agrícola e passa a desenvolver novas atividades, fazendo surgir uma nova concepção para o meio rural.

Nos Estados em que o Turismo Rural já é visto como atividade economicamente viável - Santa Catarina, Rio Grande do Sul, São Paulo - tem-se um desenvolvimento relevante aos empresários que adotaram a atividade transformando-a em uma atividade como alta rentabilidade (SILVA; CASIMIRO FILHO; LIMA, 2009, p.2)

À medida que agricultores começam a assumir novas tarefas tem-se um contíguo de novas funções no meio rural, tais modificações ocorrem além da área econômica, na área social e cultural, causando impactos positivos e negativos na população residente.

Para Schneider (2007) "a medida que as famílias conseguem ter um portfólio mais diversificado de opções de trabalho, tornando-se plurativas", ou seja, é uma unidade produtiva em que empreendem atividades agrícolas e não-agrícolas tanto dentro como fora dentro e fora da localidade. Ainda segundo o mesmo, "suas rendas tendem a se elevar, adquirir maior estabilidade, e as fontes tende a se diversificar" (SCHNEIDER, 2007, p.22).

O novo rural se insere nesse contexto, em que famílias de trabalhadores que tem suas atividades voltadas apenas para o setor agrícola, passam a adquirir novos conhecimentos e tentam combinar, desta maneira, em formas diversas de ocupação que, segundo Lacerda (2005), distribuem-se em diferentes ramos, de atividades agrícolas e não agrícolas. Estes fatos acontecem muitas vezes porque no período de estiagem a agricultura deixa de ser rentável, e também já não necessita de todo o tempo das famílias. Posto isso, serviços que estão ligados ao Turismo Rural se tornam economicamente viáveis. 
As vantagens desse tipo de turismo vão além de benefícios somente dos que empreendem nesta atividade, influenciando também na qualidade de vida do turista, na preservação ambiental, resgatando a cultura local e a popular, dentre outros.

Portuguez (2006), defende que no Ceará - assim como em algumas outras regiões - "o turismo passou a se projetar efetivamente como importante segmento do mercado nos últimos 10 anos do século XX". Atualmente, o turismo rural se caracteriza como atividade crescente e de grande importância econômica, contemplado até mesmo por políticas públicas que visam defender e apoiar a atividade. De acordo com Silva, Casemiro Filho e Lima (2010)

\footnotetext{
Com o Turismo Rural há uma oportunidade de complementação de renda em períodos críticos para tais famílias, visto que tais atividades turísticas têm seu pico máximo nos períodos em que a agropecuária no Estado está em baixa, segundo semestre do ano (SILVA; CASEMIRO FILHO; LIMA, 2009, p. 03).
}

A atividade é tida como uma estratégia que as famílias utilizam para a complementação da renda, porém tais famílias, não precisam modificar sua rotina. Assim, continuam a produção agropecuária e estimulam o desenvolvimento local, pois trocam experiências com os turistas atraídos por esta atividade econômica.

Nesse sentido, pretende-se discutir algumas conjecturas para as cidades que compõe o triangulo Crato, Juazeiro do Norte e Barbalha (CRAJUBAR) no interior do Estado do Ceará, e como a exploração do Turismo Rural sustentável é de grande valia para o desenvolvimento de famílias camponesas. Será abordado o turismo no Espaço Rural, uma vez que a caracterização do Turismo Rural restringe o campo de pesquisa, pelo fato de que esse tipo de turismo ainda é pouco explorado e divulgado e não haver trabalhos com maiores detalhes acerca do Turismo Rural propriamente dito.

\section{TURISMO RURAL E SUAS DEFINIÇÕES}

Muitas são as definições do que vem a ser o Turismo Rural, sobretudo, seus meios de utilização, se são somente as atividades campestres, ou se engloba também a hospedagem no campo.

O surgimento do Turismo Rural no Brasil se dá na década de 1980. As primeiras experiências ocorrem nos Estados do Sul do país, sendo a pioneira a Ciência e Sustentabilidade - CeS | Juazeiro do Norte v. 2, n. 1, p. 82-102, jan/jun 2016 
fazenda de Pedra Branca na cidade de Lages-SC (SIRIGADO, 2001).

Segundo Almeida e Rield (2000, p.07):

O Turismo Rural é conhecido como atividade turística que ocorre na zona rural, integrando a atividade agrícola e pecuária à atividade turística, é um fenômeno social que consiste no envolvimento dos indivíduos ou grupo de pessoas, gerando múltiplas inter-relações de importância social, economia e cultura.

Para o Ministério do Turismo no Brasil (2014), Turismo Rural é o:

Conjunto das atividades turísticas desenvolvidas no meio rural, comprometidas com a produção agropecuária, agregando valor a produtos e serviços, resgatando e promovendo o patrimônio cultural e natural da comunidade.

Oxinalde apud Graziano da Silva (2000), descreve que Turismo Rural abrange várias formas de realizar turismo "que não se excluem e que se complementam, de forma tal que o turismo no espaço rural é a soma de ecoturismo e turismo verde, turismo cultural, turismo esportivo, agroturismo e turismo de aventura".

Assim como tantas outras novas atividades desenvolvidas no campo, o Turismo Rural também pode ser visto como uma forma de complementação da renda. Porém, "a relativa inexperiência do homem do campo com atividades não tradicionais, aliadas ao desconhecimento das especificidades do Turismo Rural" (ALMEIDA e RIELD, 2000, p.09) podem gerar pontos negativos ao desenvolvimento dessa atividade.

A busca por ambientes de descanso diferentes dos habituais é um dos fatores que fazem o turista urbano optar por esse tipo de turismo. De acordo com Zimmermann e Castro (1996) as características do visitante (homem urbano), que traz em si todos os problemas vivenciados nos grandes centros urbanos (estresse, poluição, insegurança, etc.), oportunizam no Turismo Rural vivenciar o outro lado do seu cotidiano.

A partir desta experiência o homem urbano, busca, sobretudo seu bem-estar, e desta forma é possível perceber sua preocupação com o meio ambiente, em preservá-lo para que possa desfrutar deste rico ambiente não só natural (ainda mesmo que este seja um dos fatores mais relevantes) como também cultural, social. É nesse contexto que se torna possível afirmar que o Turismo Rural proporciona 
ainda a satisfação e bem-estar de todos os envolvidos no ato, desde a comunidade até quem oferece (ZIMMERMANN; CASTRO,1996).

Como atividade econômica, o Turismo Rural parece ser uma via natural para o progresso de zonas rurais desfavorecidas, permitindo aos agricultores combinar a diversificação de suas atividades com uma valorização de suas produções e de seu patrimônio cultural (ALMEIDA, 1999).

De acordo com Zimmermann e Castro (1996) "o Turismo Rural tem se revelado como uma atividade econômica completa", ou seja, seu aspecto econômico resulta em geração de divisas e receitas internas, desta forma é importante ressaltar a importância do mesmo nos períodos de estiagem, seca. Já em aspectos sociais o Turismo Rural é caracterizado como forte gerador de empregos e melhorias como qualificação da mão de obra.

Posto isso é inserido a relação dos empregos em diretos e indiretos, ou seja, a cada um emprego direto gerado em função de uma nova atividade turística e esta situada na zona rural, é gerado três novos empregos de forma indireta segundo a Organização Mundial de Turismo (OMT).

Esse tipo de turismo também tem influência na geração de novos empregos, além de melhorar a infraestrutura local, favorecer o aumento dos serviços e produtos da agropecuária e incentivar empresas relacionadas ao setor.

Segundo Silva (1999) o Turismo Rural também tem um papel fundamental na gestão territorial, uma vez que o mesmo tem a capacidade de estimular o aproveitamento do potencial endógeno de um determinado local. Tal potencial surge como uma forma de manutenção de características culturais de uma população.

Conceituado o Turismo Rural resta saber a definição do turismo no Espaço Rural, uma forma bem mais abrangente abordada neste estudo e que conforma as expectativas principais acerca da atividade que será explorada.

O Ministério do Turismo corrobora com a definição de turismo no espaço rural de Silva (1998), onde diz que:

Todas as atividades praticadas no meio não urbano, que consiste de atividades de lazer no meio rural em várias modalidades definidas com base na oferta: Turismo Rural, Turismo Ecológico ou Ecoturismo, Turismo de Aventura, Turismo de Negócios e Eventos, Turismo de Saúde, Turismo Cultural, Turismo Esportivo, atividades estas que se complementam ou não (SILVA, 1998, p.14) 
No Manual do Ministério do Turismo sobre Marcos Conceituais, as atividades turísticas no meio rural constituem-se da oferta dos seguintes elementos:

i) Hospedagem;

ii) Alimentação;

iii) Recepção à visitação em propriedades rurais;

iv) Recreação, entretenimento e atividades pedagógicas vinculadas ao contexto rural;

v) Outras atividades complementares às acima listadas, desde que praticadas no meio rural, que existam em função do turismo ou que se constituam no motivo da visitação.

\subsection{Como o Turismo Rural pode ser explorado}

É certo que a sazonalidade rural, os períodos de estiagem e o mau tempo trazem prejuízos financeiros para as comunidades rurais, principalmente àquelas onde a única renda é extraída do cultivo ou de atividades relacionadas. Ter uma experiência a qual se possa gerar renda nos períodos difíceis pode ser uma alternativa não só de suprir as necessidades em períodos de baixos rendimentos, como também ajudar a manter essas famílias no local onde vivem, evitando assim o êxodo rural e a aglomeração nas grandes cidades.

Segundo Ruschmann (2000, p.63) essa atividade de visitação às propriedades rurais não é tão nova no Brasil e no restante do mundo data-se atividades recreativas já no século XIX. Porém somente a partir de 1980 é que este segmento foi considerado uma atividade econômica e houve a sua classificação como Turismo Rural.

Para facilitar a abordagem ao mercado consumidor, é interessante a criação de segmentação, classificando as suas preferências e utilizando as ferramentas de marketing com foco em quem se deseja atingir e como. A segmentação de mercado nada mais é do que selecionar um grupo específico de consumidores que possuem necessidades, comportamentos de compra e/ou características similares (TULESKI, 2009). Com base nesse conceito Tuleski defende que segmentar é "o processo de dividir o mercado em grupos de potenciais consumidores com necessidades e/ou características similares e que estão propensos a ter um mesmo comportamento de 
compra".

Diante disso, segmentar o mercado de Turismo Rural é uma parte fundamental para transformar esse acolhimento de visitantes em um empreendimento lucrativo e sem muitos custos, já que se utiliza da paisagem local e das atividades e instalações do meio, onde o turista desse tipo de serviço não busca o luxo e sim a autenticidade rústica local com conforto e qualidade (MINISTÉRIO DO TURISMO, 2011).

Fora citado por Ruschmann (2000) no seu trabalho uma pesquisa que fora realizada nos Estados Unidos a qual difunde que os clientes que procuram pelo Turismo Rural estão descontentes com as ofertas de turismo habituais como mar e montanha. O que eles buscam, segundo a pesquisa são os aspectos simples e autênticos, característicos do dia-a-dia do meio agrícola, porém com um conforto razoável se comparado àquele de seu cotidiano.

Uma pesquisa realizada no Brasil em 2009 pelo Instituto Vox Populi sobre os hábitos de consumo de turismo do brasileiro revela que $33,9 \%$ de clientes atuais ${ }^{5}$ escolheram o Estado de destino pelo motivo de beleza natural/natureza.

Segundo o Ministério do Turismo (2014), alguns dos serviços que podem ser explorados pelo pequeno empreendedor dentro da propriedade rural seriam a hospedagem, que não precisa ser sofisticada, mas ofereça conforto, alimentação com produtos típicos, guiamento, condução e recepção para orientação individual ou em grupo de turistas e o transporte no local, que vai desde os modos urbanos como ônibus e vans, até mesmo os já oferecidos no meio, como passeio de trator ou charrete.

Além desses serviços, pode-se diversificar a estadia do visitante com outras atividades, tais como o plantio, manejo de animais (como ordenha e pesque-pague), atividades de transformação como fabricação de compotas, doces, queijos, etc.

Atividades do turismo de esporte, como trilhas, rapel, observação da fauna e da flora, reforçam o contato do turista com atividades que não são do seu cotidiano, mas que resultam em lembranças e momentos prazerosos. Desta forma, a preferência por estes locais se torna relevante, pelo alto poder de contato com a

5 Público alvo: Turistas brasileiros maiores de 18 anos, das classes A, B, C e D, com os seguintes perfis.

- Clientes atuais: consumidores que compraram serviços de turismo em pacotes ou em partes nos últimos dois anos;

- Clientes potenciais: consumidores que podem vir a comprar serviços e produtos turísticos em pacotes ou em partes nos próximosdois anos.

Ciência e Sustentabilidade - CeS | Juazeiro do Norte v. 2, n. 1, p. 82-102, jan/jun 2016 
natureza, fator este que influência diretamente no bem-estar do indivíduo.

Atividades culturais como manifestações populares, produção de artesanato, visita a museus e a gastronomia local também são uma excelente opção para aqueles que desejam sair da rotina urbana e adentrar em um mundo repleto de atividades simples, mas que podem gerar um relaxamento natural pelo contato com a vida campestre e suas rotinas.

\section{MÉTODOS E PROCEDIMENTOS}

Para dar critério científico a esta pesquisa, foi adotado alguns procedimentos apontados como os corretos e aceitaveis no mundo acadêmico, no tocante a escrita e pesquisa científica.

Para Prodanov e Freitas (2013) os métodos ciêntíficos auxiliam no esclarecimentos acerca dos procedimentos lógicos seguidos na pesquisa, no processo investigativo de cunho científico dos fatos da natureza e da sociedade. $\mathrm{Na}$ leitura dos autores

São, pois, métodos desenvolvidos a partir de elevado grau de abstração, que possibilitam ao pesquisador decidir acerca do alcance de sua investigação, das regras de explicação dos fatos e da validade de suas generalizações. (PRODANOV; FREITAS, 2013, p. 26)

Os métodos utilizados para os fins desta pesquisa foram o exploratório e o indutivo.

Quanto aos fins da pesquisa, foi escolhido o método exploratório porque "Visa a proporcionar maior familiaridade com o problema, tornando-o explícito ou construindohipóteses sobre ele" (PRODANOV; FREITAS, 2013).

A escolha do método de abordagem indutivo, adveio da observação dos autores, onde defende que no método indutivo, "[...] partimos da observação de fatos ou fenômenos cujas causas desejamos conhecer" (PRODANOV; FREITAS, p. 57).

Os meios técnicos utilizados foram o estatístico e o comparativo. Ambos contribuem para uma boa análise de dados secundários. "O papel do método estatístico é, essencialmente, possibilitar uma descrição quantitativa da sociedade, considerada como um todo organizado" (PRODANOV; FREITAS, 2013). Os autores afirmam que "o método comparativo, ao ocupar-se das explicações de fenômenos, permite analisar o dado concreto, deduzindo elementos constantes, abstratos ou gerais nele presentes". 


\subsection{Caracterização da Área de Estudo}

A Região do Cariri faz parte de uma extensa área de uma das microrregiões no Estado do Ceará, que segundo o IBGE, essa região possui uma área total de $4.115,828 \mathrm{~km}^{2}$, pertence à Mesorregião Sul Cearense.

Em junho de 2009, foi aprovada na Assembleia Legislativa do Ceará a mensagem do Executivo que cria a Região Metropolitana do Cariri. A autonomia do Cariri esteve sempre ancorada, pela condição geoambiental da região que the conferia um destaque como ilha natural e de prosperidade em meio ao sertão árido do Nordeste (QUEIROZ, 2013).

A Região do cariri vem crescendo economicamente, tornando-se destaque social em geração de empregos e renda. Segundo informações do IBGE, a cidade de Juazeiro do Norte assim como o Crato e Barbalha desenvolve-se a passos rápidos, à medida que as cidades periféricas como Nova Olinda, Santana do Cariri, Farias Brito, Missão Velha, Jardim e Caririaçu, mesmo que próximas não se desenvolvem de forma integrada (IBGE, 2014).

Desta forma é importante mencionar que Juazeiro do Norte funciona como polo de grande desenvolvimento para os municípios do sul do Estado do Ceará e regiões circunvizinhas, acompanhado pela cidade de Crato e Barbalha. Ponto central da conturbação que deu origem ao termo CRAJUBAR.

Ao analisar o mapa da RM Cariri (Figura 01) obtido através do Instituto Brasileiro de Geografia e Estatística (IBGE), Instituto de Pesquisa e Estratégia Econômica do Ceará (IPECE) pode-se notar que, apesar do município de Juazeiro do Norte ser territorialmente menor que os demais, é destaque pelo grande potencial em desenvolvimento na região. 


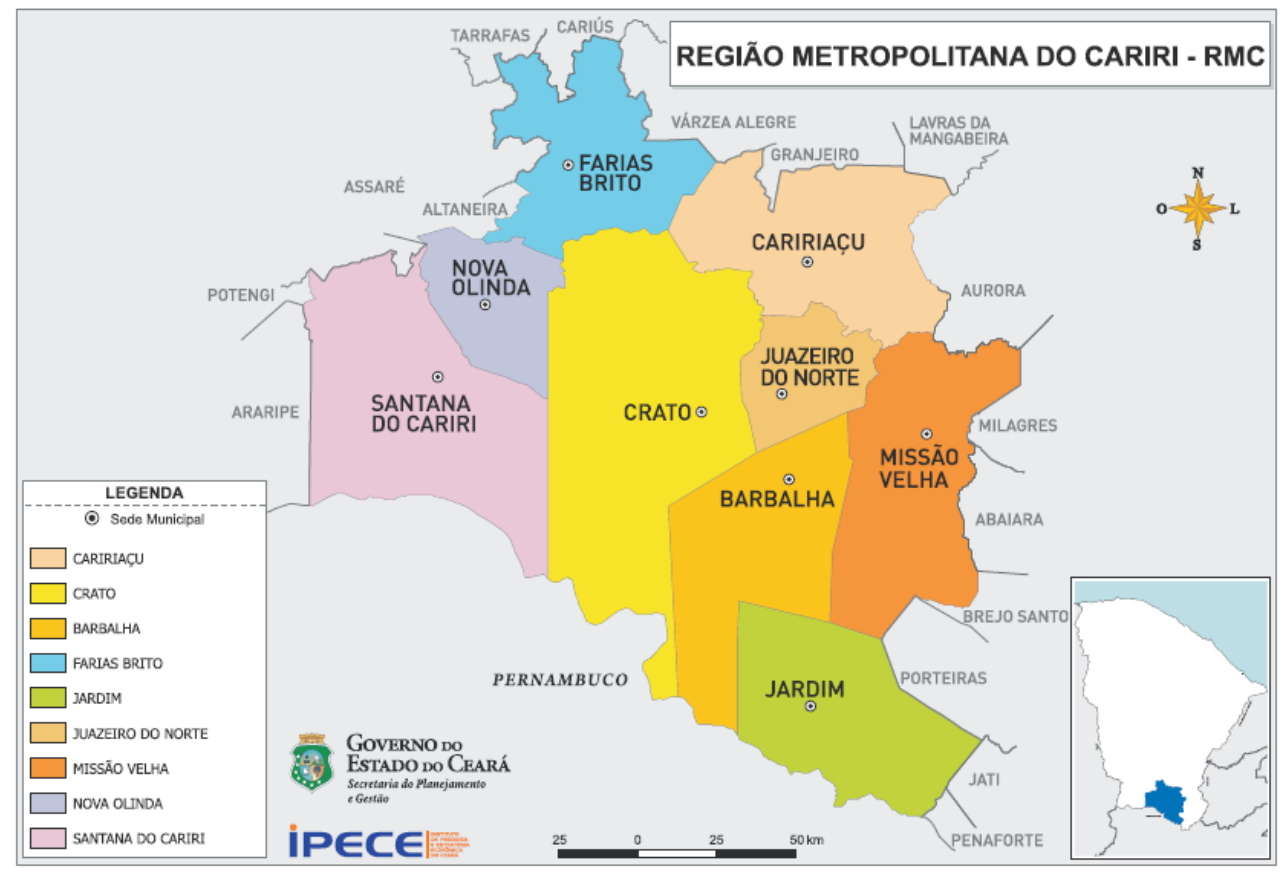

FIGURA 01: Mapa da Região Metropolitana do Cariri - RMC

Fonte: Instituto Brasileiro de Geografia e Estatística (IBGE), Instituto de Pesquisa e Estratégia Econômica do Ceará (IPECE) 2014.

O Triângulo CRAJUBAR, é situado na parte central da RMC, composto pelas cidades de Crato, Juazeiro do Norte e Barbalha, possuem uma população de aproximadamente 426.690 habitantes, segundo dados do IPECE (2010). Juazeiro do Norte destaca-se por ocupar o lugar de terceira maior cidade do Estado (IBGE, 2010). Como principais características, este município possui um elevado dinamismo comercial, influenciado pelo turismo religioso que a cidade oferece através das romarias criadas a partir da imagem do Padre Cícero.

De acordo com Carvalho et al. (1998, p.2), "geograficamente o Triângulo CRAJUBAR está situado na Região do Cariri cearense, distando em média, $612 \mathrm{Km}$ de Fortaleza, Recife, João Pessoa, Natal e Teresina e um pouco mais de Salvador. São Paulo está a 3800 Km e Rio de Janeiro a 3000 Km." 


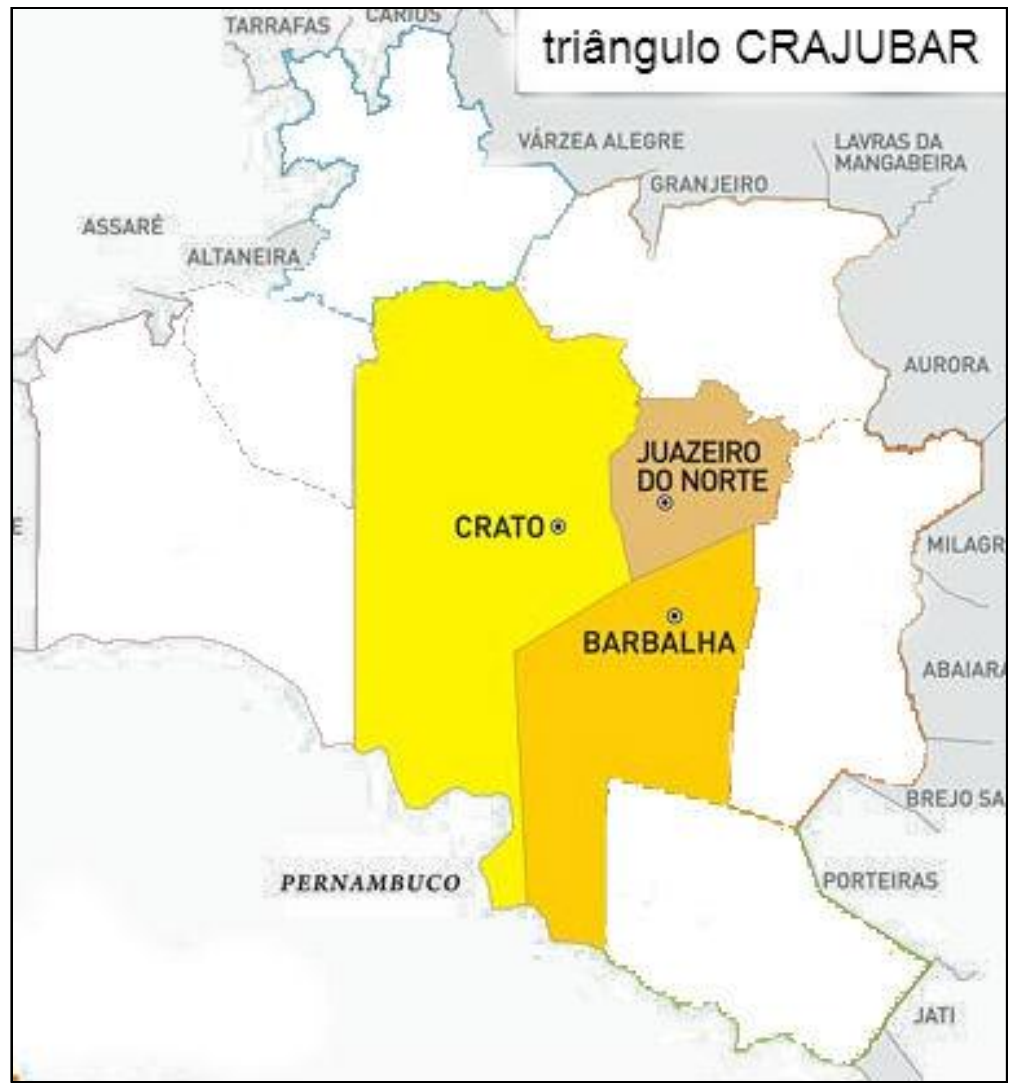

FIGURA 02: Mapa da Conurbação CRAJUBAR

Fonte: IPECE (2014). Organizado pelos autores.

A cidade de Juazeiro do Norte possuía no ano de 2010 uma população de 249.939 habitantes com uma estimativa, segundo o IBGE Cidades, de mais de 263 mil habitantes para o ano de 2014. No mesmo ano, o número de habitantes da zona rural de Juazeiro era de 9.815 , representando $3,93 \%$ do total da população. O Valor adicionado do Produto Interno Bruto (PIB) neste mesmo ano na agropecuária foi de $\mathrm{R} \$ 5.910,00$ de um total $\mathrm{R} \$ 1.966 .331,00$ geral, o que representa $0,3 \%$ do PIB total. O PIB per capita em 2010 fora de $\mathrm{R} \$ 602,20$ contra $\mathrm{R} \$ 8188,82$ do restante da população (indústria e comércio). Está localizada na Região Sul do Estado do Ceará, e faz fronteira com as cidades de Crato, Barbalha, Missão Velha e Caririaçu.

O Município de Barbalha, no último censo (2010) teve contabilizados 55.323 habitantes, com estimativas para o ano de 2014 de 58.347. O PIB em 2011 fora de 455.763 mil reais, dividido em 11.772 mil reais para a agropecuária (2,58\%), 138.755 mil reais para a indústria $(30,45 \%)$ e 305.236 mil reais para o comércio $(66,97 \%)$. 0 PIB per capita em 2011 era de $\mathrm{R} \$ 8.681,00$.

O Município do Crato possuía no último Censo (2010), 121.428 habitantes, seu PIB a preços correntes era de 932.173 mil reais, sendo que o PIB agropecuário 
representava $2,35 \%$, totalizando 21.879 mil reais. O PIB industrial representou uma valia de $18,4 \%$ (171.560 mil reais) enquanto que 642.988 mil reais expressavam $79,25 \%$ do total do PIB do comércio.

O Crato Localiza-se no sopé da Chapada do Araripe no extremo-sul do Estado e na Microrregião do Cariri. Faz limites territoriais no Ceará com as cidades de Santana do Cariri, Nova Olinda, Farias Brito, Várzea Alegre, Barbalha, Juazeiro do Norte e Caririaçu. Seus limites com o Pernambuco são com as cidades de Exu e Moreilândia onde constitui também um entroncamento rodoviário que a interliga ao Piauí, Paraíba e Pernambuco, além da capital do Ceará, Fortaleza. Conhecido como o "Oásis do Sertão" devido as suas características climáticas mais úmidas e favoráveis à agropecuária.

\section{A EXPLORAÇÃO DO TURISMO RURAL NO CRAJUBAR: POSSIBILIDADES E UMA ABORDAGEM EXPLORATÓRIA}

\subsection{Um Breve Panorama Sobre o Turismo no Interior}

De acordo com as informações obtidas através da Secretaria de Turismo do Ceará (SETUR/CE), alguns esforços são realizados para a interiorização do turismo como forma de desconcentração da renda gerada pelo turismo na capital. No ano de 2008 , cerca de $65,3 \%$ dos turistas que visitaram a capital cearense visitaram outras cidades do interior. As taxas de variação do fluxo desses turístas estão destacadas a seguir na figura 03. 


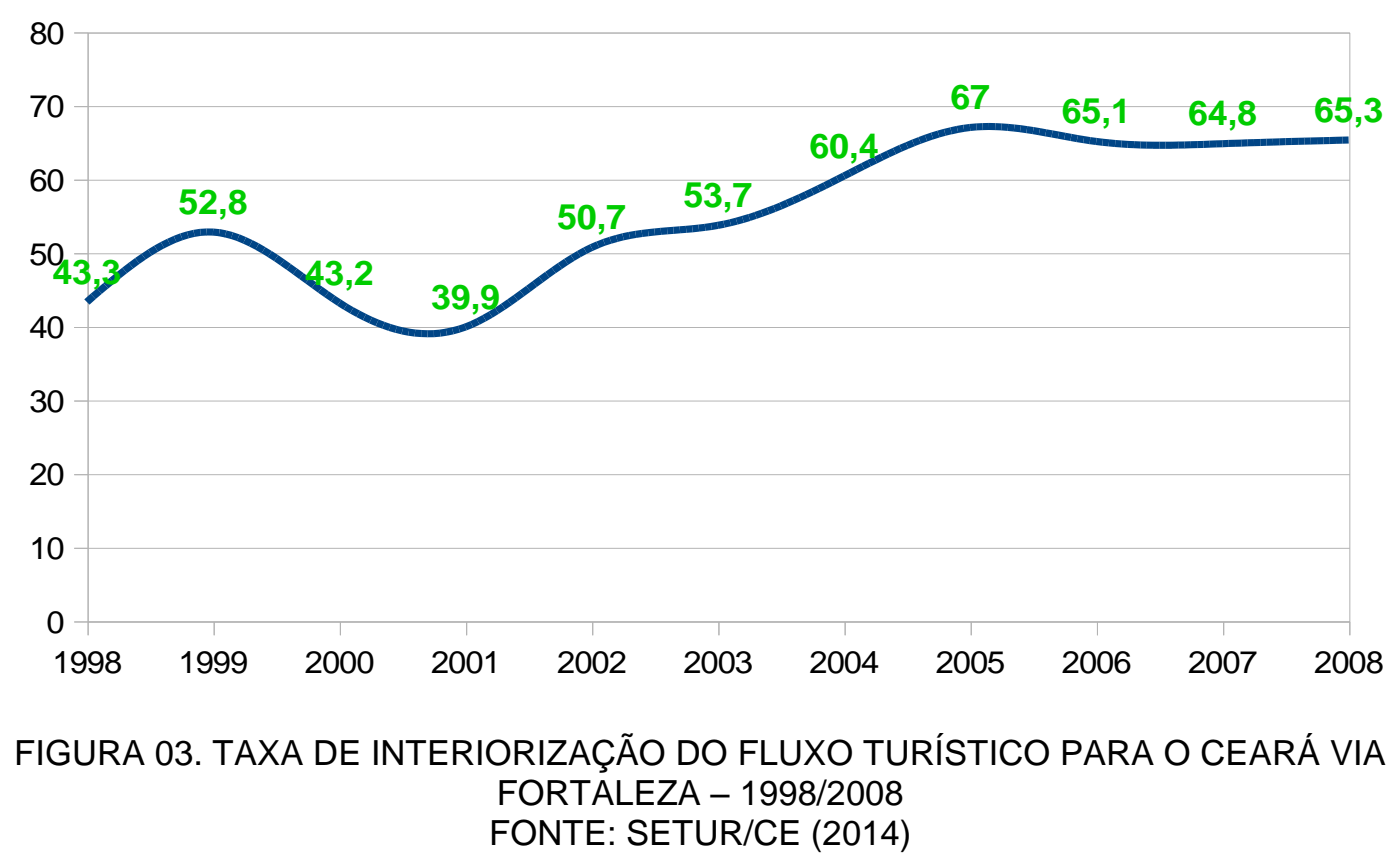

Pode-se verificar através da figura, ape'sar de leve declínio no período observado, um tendência crescente da taxa de interiorização do fluxo turístico via Fortaleza. No período de 10 anos, esse fluxo teve uma variação de 22 pontos percentuais, uma média de 2,2 ao ano. Isso significa que o processo de interiorização do turismo está em constante crescimento no Ceará, o que beneficiará a economia de cidades menores, com menos fluxo de turistas, alavancando o comércio entre outras atividades direta ou indiretamente ligadas as setor turístico.

Para a SETUR p. 6),

[...] a interiorização do turismo visa, entre outros objetivos, desconcentrar espacialmente os impactos da receita gerada pelos turistas que se destinam a Fortaleza, bem como aumentar seu tempo de permanência no Estado. O reflexo dos esforços, neste sentido, pode ser percebido no percentual de turistas que visitaram cidades e localidades fora da capital (interior) [...]

O número de estabelecimentos com hospedagem em Juazeiro do Norte, só no ano de 2012, estava entre 19 e 39 estabelecimentos de acordo com a figura 1. Esse número é bem expressivo uma vez que em todo o Estado, apenas dez municípios (incluindo Juazeiro) possui esse número de estabelecimentos para se hospedar. Já nos municípios de Barbalha e Crato, ainda que em número inferior, possuem entre 5 e 18 estabelecimentos para hospedagem cada uma. Apenas 32 municípios cearenses (incluindo esses dois últimos) possuem esse número de estabelecimentos com hospedagem. 


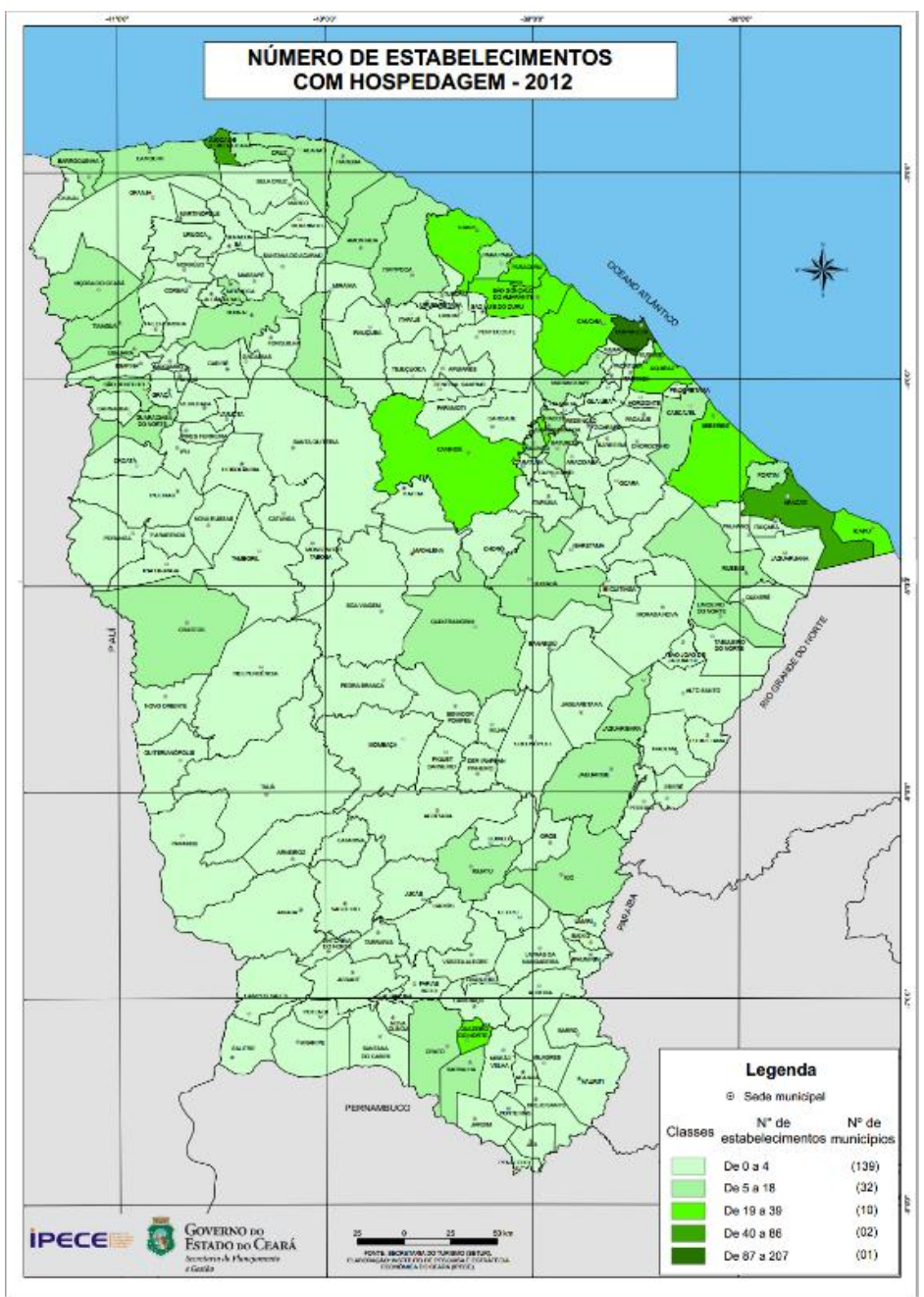

FIGURA 03: Número de Estabelecimentos com hospedagem (2012). Fonte: IPECE 2014

É possível verificar segundo relatório executivo de pesquisa sobre a Caracterização e Dimensionamento do Turismo Doméstico no Brasil (2010/2011) realizada pela Fundação Instituto de Pesquisas Econômicas (Fipe), diversos aspectos importantes sobre o turismo no Brasil. Uma delas é a característica brasileira de turismo doméstico e suas potencialidades. Segundo esse estudo, é possível afirmar que no ano de 2011, a cada 100 domicílios (a nível de população urbana brasileira), em 44 deles, pelo menos 1 de seus residentes realizou pelo menos 1 viagem doméstica; em 7 deles, pelo menos 1 de seus residentes realizou viagens rotineiras e 4,3 deles, pelo menos um residente fez uma viagem internacional.

Esses números são importantes porque mostram o quão disponível para viagens domésticas o brasileiro está. No caso cearense, os principais emissores de 
turistas para o Estado são do próprio Estado, que representam $52,7 \%$ do total de turistas, cerca de 5.812 .000 versus viagens domésticas. Os gastos médios na principal viagem doméstica segundo a mesma pesquisa, está dividida de acordo com o gráfico 1.

Gráfico 1: Gasto médio na principal viagem doméstica, por renda, segundo UF de destino Ceará

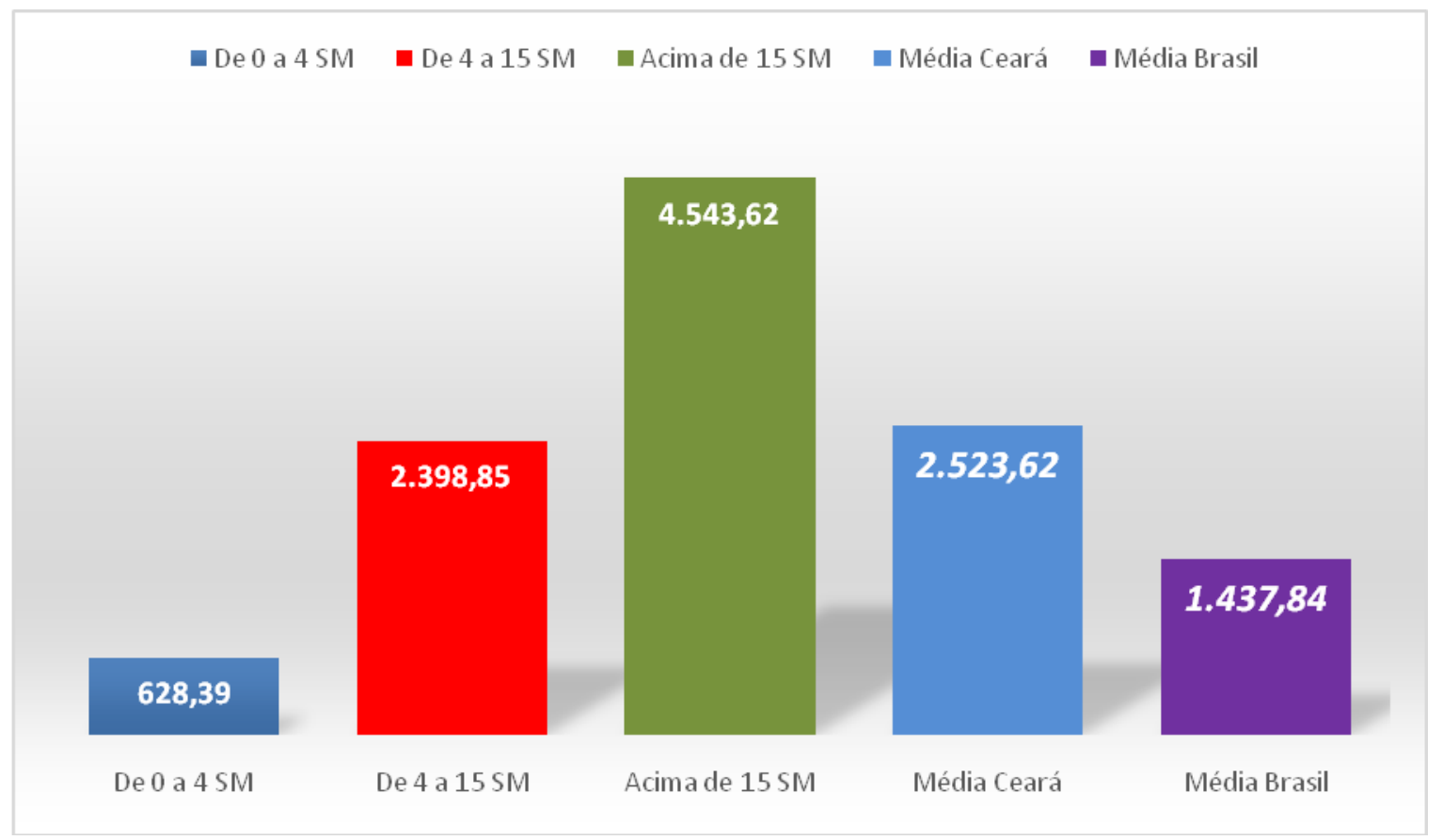

Fonte: (FIPE 2012). Organizado pelo autor.

A cidade de Juazeiro do Norte é conhecida mundialmente pelo seu turismo religioso, onde se destacam as atrações turísticas a visitação às igrejas centenárias, tais como a Basílica Menor de Nossa Senhora das Dores e a Capela de Nossa Senhora do Perpétuo Socorro. A visitação a estátua do Padre Cicero Romão Batista localizada na colina do Horto também é atrativo para os visitantes desse tipo de turismo.

Barbalha por possuir um clima mais ameno, possui balneários com fontes naturais como o Balneário do Caldas, localizado na subida da serra na CE 386 e parque aquático com áreas de preservação, como o Arajara Park, localizado a 14min deste Balneário de carro pela CE 386.

$\mathrm{Na}$ entrada da cidade, existe um lugar chamado Sitio Pinheiros, um hotel aberto à visitação, acampamento e lazer além das atividades próprias de hotel. Por sua beleza natural é local de bastante procura e visitação, servido inclusive de Ciência e Sustentabilidade - CeS | Juazeiro do Norte v. 2, n. 1, p. 82-102, jan/jun 2016 
cenário fotográfico pré-nupciais, gestacionais, de aniversário, entre outros.

O município do Crato possui também excelentes locais para desenvolvimento do Turismo Rural, como trilhas na chapada do Araripe (trilha do Belmonte, etc.).

A articulação bem estruturada do desenvolvimento do Turismo Rural nesses locais, atrelado a uma boa política de incentivo ao turismo, poderá atrair bem mais visitantes pressurosos por esse tipo de atração.

Não se pretende excluir ou dividir o turismo atrativo das cidades estudadas, e sim mostrar a capacidade que elas têm de diversificar a oferta atual, aumentando possivelmente o fluxo de turistas e consequentemente aumentando o emprego e a renda, principalmente na área rural.

\subsection{Turismo Rural no CRAJUBAR}

Conjecturando a disponibilidade de gastos do turista dos últimos anos com visitação fora da capital no Ceará, vislumbrando também que à esse mesmo turista deve-se um acréscimo significativo na procura pelo interior do Estado para turismo e tendo em vista que o acesso as cidades do CRAJUBAR atualmente, tanto por meio aéreo quanto terrestre está cada vez mais fácil, frequente e barato, interligando regiões de alto fluxo de tráfego aéreo do país como Brasília, Fortaleza e Recife, além de localização privilegiada terrestre (localizada à menos de $700 \mathrm{~km}$ das capitais nordestinas, excetuando-se São Luis/MA e Salvador/BA), é que se verifica o quão a região poderá ter implementadas políticas de desenvolvimento do Turismo Rural bem mais eficientes e geradoras de renda e riqueza local.

A parceria com empresas de turismo é importante para ajudar na divulgação dos pontos turísticos da cidade. A divulgação proporciona estímulo e interesse ao turista para conhecer os pontos de Turismo Rural no CRAJUBAR. É de suma importância, pois beneficia a população gerando cada vez mais renda e empregos diretos e indiretos oriundos da atividade turística, de modo também a fixar esses rendimentos no âmbito rural.

Já é desenvolvido na região, na cidade de Juazeiro do Norte, desde a época do Padre Cícero Romão Bastista, um turismo religioso fervoroso, mais conhecido regionalmente como as romarias. As romarias reunem cerca de meio milhão de pessoas por romaria e acontecem 3 grandes encontros durante o ano: na semana 
santa, onde a concentração está na ladeira do horto onde está localizada a estátua do Padre Cicero e o caminho para o santo sepulcro, a romaria das candeias em fevereiro e em setembro, na festa de nossa senhora das Dores.

Apesar desses três grandes momentos de receptividade turística, Juazeiro do Norte recebe turistas em pequena escala durante todo o ano. O mesmo acontece na cidade de Barbalha e os balneários de fontes naturais. O Crato e suas belas trilhas ecológicas que cercam a chapada do Araripe, danto uma visão deslumbrante para os frequentadores desse tipo de atividade.

Faz-se necessário a integração das comunidades locais com as propriedades rurais por meio do desenvolvimento do turismo campesino, aumentando a autoestima do homem do campo e valorizando as práticas do meio rural. Para isso é preciso que autoridades locais percebam o quão importante para o desenvolvimento agrário são atividades afora aquelas já cultivadas na agricultura.

Esse turismo irá proporcionar ao homem do campo um maior contato com o seu consumidor, seja ele das atividades campestres, seja dos produtos produzidos na lavoura.

\section{CONSIDERAÇÕES FINAIS}

A região semiárida do Nordeste do Brasil, mais precisamente o sertão, é caracterizada pela pouca quantidade de precipitação, além de serem irregulares durante $\mathrm{o}$ ano. Ainda que haja uma agenda de previsões mais otimistas, "a probabilidade que elas ocorram é uma evidência, uma contingência da natureza desta parte do país" (CASTRO, 2008, p.3). Essa especificidade regional acarreta dois imaginários: um fenômeno da natureza que castiga o homem nordestino, e ou outro pensamento, cujo anda par com a defesa desse clima que desponta para o turismo, considerada como uma das atividades que possui vantagens comparativas junto ao agrobusiness (CASTRO, 2008).

Não excluindo a responsabilidade pública de se fazer políticas para a prevenção de perda e organização prévia do meio rural e todas as suas peculiaridades, é necessário também que se reforce as atividades que estão além da capacidade da terra em gerar renda. É nesse tocante que surge o turismo no espaço rural como fonte alternativa.

Ciência e Sustentabilidade - CeS | Juazeiro do Norte v. 2, n. 1, p. 82-102, jan/jun 2016 
A região CRAJUBAR tem um aspecto que the é peculiar: localizada as margens da chapada do Araripe, com clima "sem chuva" praticamente o ano todo, o que facilitaria o tráfego de pessoas para as visitas aos mais diversos pontos da zona rural, uma vez que a possibilidade de precipitação é muito insipiente.

Essa localização proporciona também, a facilidade de visita as zonas rurais do seu entorno (missão Velha, Brejo Santo, Farias Brito, entre outras) contribuindo para a desconcentração do consumo desse tipo de atividade, tão comum na zona litorânea brasileira.

Essa combinação deve ter como objetivos a agregação de valor ao espaço rural, a verticalização da produção para disponibilizar aos turistas como forma de geração de renda extra bem como a interatividade campo-cidade.

\title{
SUSTAINABLE DEVELOPMENT AND TOURISM IN RURAL AREA: AN EXPLORATORY PERSPECTIVE AT THE TRIANGLE CRAJUBAR
}

\begin{abstract}
It has tourism as a new form of non-agricultural employment in the rural areas, being the subject of great debate and making occurs public policy actions for the development of the field. As a global economic sector branch fastest growing, rural tourism in the State of Ceará, brings local development and generate employment and income. The aim of this paper is to discuss some proposals for the municipalities that make up the Crato triangle, Juazeiro and Barbalha (Crajubar), within the State of Ceará, and how the exploitation of sustainable rural tourism is of great value to the development of families peasant. We chose an explanatory analysis methodology, exposing only a few issues, for the operation of this form of tourism is just beginning to gain strength in the region. Having the notion that rural tourism is an important development tactics of small and medium farmers open up space to discuss public policies that suit the region, making this form of tourism will become even more room, and so, therefore besides the development of the rural development of the region as a whole.
\end{abstract}

Key Words: Sustainable development. Rural tourism. Crajubar.

\section{REFERÊNCIAS}

MINISTÉRIO DA EDUCAÇÃO - MEC. Agropecuária do Estado do Ceará. SEADE. [199?] Disponível em: <http://portal.mec.gov.br/setec/arquivos/pdf/agropec_ce.pdf>. Acesso em 15/08/2014.

ALMEIDA, J. A. Turismo Rural: uma estratégia de desenvolvimento via serviços. In: CONGRESSO BRASILEIRO DE TURISMO RURAL. 1999, Piracicaba. Anais do congresso brasileiro de Turismo Rural: turismo no espaço rural brasileiro / [ed] Cássio Garkalns de Souza Oliveira. FEALQ, 1999 
ALMEIDA, J. A.; RIELD, M. (Orgs.). Turismo Rural: ecologia, lazer e desenvolvimento. Bauru: EDUSC, 2000. 264 p.

BANCO DE DADOS DE INDICADORES SOCIOECONÔMICOS DA REGIÃO DO CIPP. Disponível em: <http://cipp.ipece.ce.gov.br/mappav/vi/serie.php?idResult=3>. Acesso em: 05/08/2014.

IBGE. Perfil Econômico e infográficos da cidade de Barbalha. Disponível em: $<$ http://cidades.ibge.gov.br/xtras/perfil.php?lang=\&codmun=230190\&search=ceara|b arbalha>. Acesso em: 06/09/2014.

. Juazeiro do Norte, Ceará. Cidade. In Atrações Turísticas.

Disponível em: http://www.juazeiro.ce.gov.br/Cidade/Atracoes-turisticas/.Acesso em 06/09/2014.

Perfil Econômico e infográficos da cidade do Crato. Disponível em: $<$ http://cod.ibge.gov.br/2JYL0>. Acesso em: 06/09/2014.

. Perfil Econômico e infográficos da cidade de Juazeiro do Norte. Disponível em: <http://cod.ibge.gov.br/234FL> Acesso em: 06/09/2014.

LACERDA, Tatiane Ferreira Nobre de; MARQUES, Paulo Eduardo Moruzzi; SCHNEIDER, Sergio. A unidade familiar e as novas funções atribuídas à agricultura: o caso dos agricultores ecológicos do território da Encosta da Serra Geral. Rio Grande do Sul: UFRGS, 2005. 170f. Dissertação - Programa de PósGraduação em Desenvolvimento Rural, Faculdade de Ciências Econômicas, Universidade Federal do Rio Grande do Sul, Porto Alegre, 2005.

MAPAS Geográficos das cidades de Juazeiro do Norte, Barbalha e Crato. Disponível em: <https://www.google.com.br/maps/>. Acesso em: 06/09/2014.

MINISTÉRIO DO TURISMO. Caracterização e Dimensionamento do Turismo Doméstico No Brasil - 2010/2011. Relatório Executivo - Produto 6. São Paulo. FIPE, 2012.Disponívelem:

$<\mathrm{http}: / / \mathrm{www}$.dadosefatos.turismo.gov.br/export/sites/default/dadosefatos/demanda_t uristica/downloads_demanda/Demanda_domxstica_-_2012_-

_Relatxrio_Executivo.pdf>. Acesso em: 07/08/2014.

MINISTÉRIO DO TURISMO. Marcos Conceituais. In: Cadernos e manuais de segmentação. 2015. Disponível em:

<http://www.turismo.gov.br/sites/default/turismo/o_ministerio/publicacoes/downloads

Ciência e Sustentabilidade - CeS | Juazeiro do Norte v. 2, n. 1, p. 82-102, jan/jun 2016 
Camila Pereira Brigido Rodrigues; Denis Fernandes Alves; Maria Daniele Cruz dos Santos; José Márcio Santos

_publicacoes/Marcos_Conceituais.pdf> Acesso em 30/06/2016.

PORTUGUEZ, Anderson Pereira. Turismo no espaço rural: enfoques e perspectivas.[et.al.]. - São Paulo: Roca, 2006.

PREFEITURA MUNICIPAL DO CRATO. A cidade. Disponível em <http://www.crato.ce.gov.br/index.php/a-cidade>. Acesso em: 06/09/2014.

PRODANOV, Cleber Cristiano; DE FREITAS, Ernani Cesar. Metodologia do Trabalho Científico: Métodos e Técnicas da Pesquisa e do Trabalho Acadêmico. 2ª Edição. Editora Feevale, 2013.

QUEIROZ, Ivan da Silva. A metrópole fora do eixo: a emergência da região metropolitana do cariri cearense no âmbito estadual. In: XIII SIMPURB - UERJ. Rio de Janeiro, 2013. Disponivel em: <http://www.simpurb2013.com.br/wpcontent/uploads/2013/11/1652_Ivan.pdf>. Acesso em: 15/08/2014

RUSCHMANN, Doris Van de M. O Turismo Rural e o Desenvolvimento sustentável. . In: ALMEIDA, Joaquim Anécio; FROEHICH, Jose Marcos; RIEDL, Mário. (orgs).

Turismo Rural e Desenvolvimento Sustentável. 2ª . Edição. Campinas, SP. Papirus, 2000 - Coleção turismo. P. 63-74.

.; VILARINHO, Carlyle; DALE, Paul J. Turismo em áreas rurais: suas possibilidades e limitações no Brasil. In: ALMEIDA, Joaquim Anécio; FROEHICH, Jose Marcos; RIEDL, Mário. (orgs). Turismo Rural e Desenvolvimento Sustentável. 2ª . Edição. Campinas, SP. Papirus, 2000 - Coleção turismo. P. 15-62.

SETUR/CE - SECRETARIA DO TURISMO NO CEARÁ. Evolução Recente do Turismo no Ceará. 2009 Disponível em:

$<$ http://www.setur.ce.gov.br/categoria1/estudos-e-

pesquisas/Evolucao\%20do\%20Turismo\%20no\%20Ceara\%20Volume\%2017.pdf>. Acesso em: 30/06/2014.

SILVA, Thiago Nascimento; CASIMIRO FILHO, Francisco; LIMA, Patricia Veronica Pinheiro Sales. Turismo Rural: uma estratégia de desenvolvimento rural para o assentamento Coqueirinho-Fortim/CE. In: Congresso da Sociedade Brasileira de Economia, Administração e Sociologia Rural - SOBER, 48., 2009, Campo Grande, 2009.

SILVA, José Graziano da. O novo rural brasileiro. Campinas: Unicamp - Instituto de Economia, 1999. (Coleção Pesquisas, 1). 
SILVA, José Graziano da. et al. Turismo em áreas rurais: suas possibilidades e limitações no Brasil. In: ALMEIDA, J.A. et al. (Org.). Turismo Rural e

Desenvolvimento Sustentável. Santa Maria: Centro Gráfico,1998, p. 14.

SIRIGADO, José Rafael. Espaço turístico e desenvolvimento no Cone Leste Paulista. In: RODRIGUES, Adyr Balastreri (organizador).Turismo Rural: práticas e perspectivas. São Paulo: Contexto, 2001. - (Coleção Turismo Contexto).

TULESKI, Yumi Mori. Segmentação de Mercado.CEDET - Centro de Desenvolvimento Profissional e Tecnológico. 2009. Disponível em: $<$ http://www.cedet.com.br/index.php?/Tutoriais/Marketing/segmentacao-demercado.html>.Acesso em 14/08/2014.

ZIMMERMANN, A; CASTRO, I.C. Turismo Rural: um modelo brasileiro. Florianópolis. Editora do Autor. 1996 